\title{
Variable Origin and Ramification Pattern of the Lateral Femoral Cutaneous Nerve: A Case Report and Neurosurgical Considerations
}

\section{Lateral Femoral Kütanöz Sinirin Değiş̧en Kökeni ve Dallanma Paterni: Bir Olgu Sunumu ve Nöroşirürji ile İlgisi}

Konstantinos NATSIS, George PARASKEVAS, Maria TZIKA, Efthymia PAPATHANASIOU

Aristotle University of Thessaloniki, Department of Anatomy, Thessaloniki, Greece

Corresponding Author: Konstantinos NATSIS / E-mail: natsis@med.auth.gr

\begin{abstract}
Variations in the anatomy of the lateral femoral cutaneous nerve (LFCN) have been reported in the literature. LFCN is vulnerable to injury during several surgical operations, therefore any surgeon intervening in the area should be familiar to its topographic variability. Lesion of the nerve leads to a condition known as "meralgia paresthetica". We present a cadaveric case of a variant LFCN where two LFCN branches were encountered arising from the lumbar plexus. In specific the anterior LFCN branch originated from the femoral nerve, whereas at the level of the inguinal ligament, four nerve branches were present. The existence of multiple LFCN branches could lead to diagnostic confusion in case of "meralgia paresthetica", while if the neurosurgeon is not aware of the potential variability during surgical decompression of the nerve, postoperative complications may occur. The supernumerary LFCN branches could be identified by ultrasound imaging and be used as optimum vascularized grafts for sensory nerve repair.
\end{abstract}

KEYWORDS: Lateral femoral cutaneous nerve, Multiple branches, Origin, Femoral nerve, Meralgia paresthetica, Nerve grafting

öz

Lateral femoral kütanöz sinir (LFKS) anatomisindeki değişiklikler literatürde bildirilmiştir. LFKS birçok cerrahi işlem sırasında yaralanabilir ve bu nedenle bölgede bir girişim yapan cerrahın topografik değişkenliğe aşina olması gerekir. Sinir lezyonu "meralgia paresthetica" denilen bir duruma neden olur. İki LFKS dalının lumber pleksustan çıktığının görüldüğü bir kadavra varyant LFKS vakası sunuyoruz. Özellikle anterior LFKS dalı femoral sinirden inguinal ligaman seviyesinde çıkarken dört sinir dalı mevcuttu. Çok sayıda LFKS dalının bulunması "meralgia paresthetica" durumunda diagnostik karışıklığa yol açabilir ve cerrah sinirin cerrahi dekompresyonu sırasında olası değişkenlikten haberdar değilse postoperatif komplikasyonlar oluşabilir. Fazla LFKS dalları ultrason görüntülemeyle tanımlanabilir ve duyusal sinir tamiri için optimum vaskülerize greftler olarak kullanılabilir.

ANAHTAR SÖZCÜKLER: Lateral femoral kütanöz sinir, Çoklu dallar, Köken, Femoral sinir, Meralgia paresthetica, Sinir grefti

\section{INTRODUCTION}

The lateral femoral cutaneous nerve (LFCN) typically arises from the lumbar plexus and after an intrapelvic course, passes underneath or pierces the inguinal ligament (IL) and supplies the anterolateral aspect of the thigh divided into an anterior and a posterior branch $(8,17)$. Variability of the LFCN origin, course and distribution pattern has been reported in the literature, while origin from the femoral nerve has rarely been documented. Lesion or entrapment of the LFCN may lead to a condition known as "meralgia paresthetica", a term that is derived from the Greek words "meros" and "algos" which mean thigh and pain, respectively (5). The neurological disorder is also known as "Bernardt-Roth syndrome", has an incidence rate of 4.3 per 10.000 person years (16) and includes paresthesia, hypesthesia and numbness over the LFCN supplied region (5).
The nerve is vulnerable to traction and injury during multiple surgical operations undertaken in the pelvic and femoral region and therefore anyone intervening in the area should be familiar with its anatomic and topographic variability. We present a cadaveric case of a variant LFCN where the anterior branch was found originating from the femoral nerve, whereas at the level of the IL, four nerve branches were present.

\section{CASE PRESENTATION}

An unusual case of a variant LFCN origin and topography was detected during a routine dissection of a 37-years-old, formalin-fixed, female cadaver, utilized for gross anatomy course at the Laboratory of Anatomy, Medical School of Aristotle University, Thessaloniki. By means of standard anatomical method of dissection, the anterior abdominal wall was incised, whereas the abdominal organs and the 
retroperitoneum were removed in order to visualize clearly the branches of the lumbar plexus. In addition, in the femoral region, the fascia lata was excised carefully in order not to damage the LFCN branches. Two LFCN branches were found at the right side originating from the lumbar plexus; the lateral LFCN branch had a standard origin from the L2/L3 roots and emerged non-typically from the anterior aspect of the major psoas muscle just laterally to the musculotendinous junction of the minor psoas. The second LFCN branch arose from the femoral nerve $1.1 \mathrm{~cm}$ laterally to the lateral border of the major psoas muscle (Figure 1). Both nerve branches coursed underneath the iliac fascia, following an anterior, inferior and lateral direction, towards the IL, where they converged. At the IL level, the lateral and medial LFCN branch lay $1.8 \mathrm{~cm}$ and 2.2 $\mathrm{cm}$ medially to the anterior superior iliac spine, respectively. The nerves were found passing underneath the $\mathrm{IL}$, while at the IL level, the lateral nerve divided into two rami, an anterior and a posterior one, taking the place of the typical posterior LFCN branch, while the nerve originating from the femoral nerve took the place of the anterior branch of the LFCN and immediately divided into a lateral and a medial branch. As a result, at the level of the $\mathrm{IL}$, four nerve branches were present

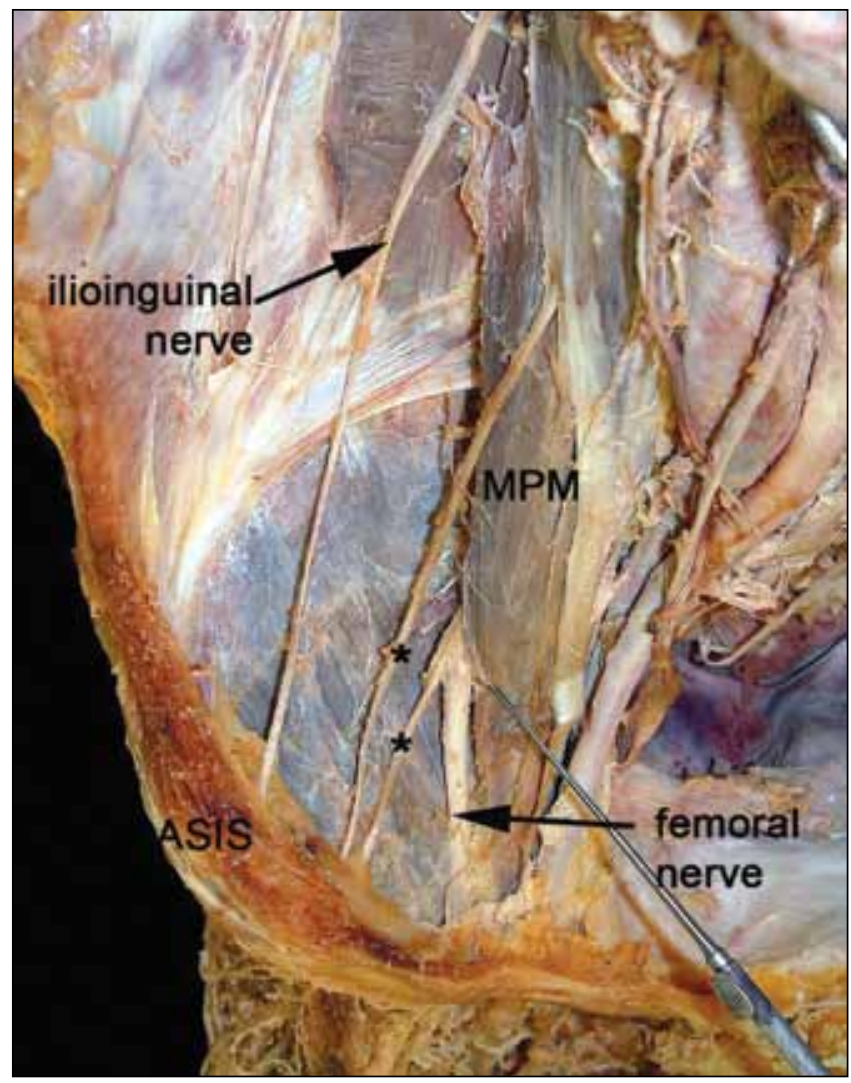

Figure 1: Intrapelvic course of the two LFCN branches $\left(^{*}\right)$ until the inguinal ligament. The lateral nerve had a typical origin from the $L 2 / L 3$ roots and passed over the major psoas muscle (MPM), while the medial one originated from the femoral nerve. At the inguinal ligament level, the lateral and medial LFCN branch lay $1.8 \mathrm{~cm}$ and $2.2 \mathrm{~cm}$ medially to the anterior superior iliac spine (ASIS), respectively.
(Figure 2). The nerves were located laterally to the sartorius muscle and innervated the anterolateral aspect of the thigh (Figure 3). The abdominal wall and cavity as well as the femoral region did not demonstrate any scars from previous operative procedures, while no space-occupying masses were detected in these areas. The precise topographic anatomy of the LFCN branches was documented by repeated photographs, whilst measurements were made with the assistance of a metric electronic digital caliper (Mitutoyo-Co, Japan) with an accuracy of $0.01 \mathrm{~cm}$.

\section{DISCUSSION}

Variations in the anatomy of the LFCN have not infrequently been documented in the literature. It has been reported that the LFCN was found passing posterior to $\mathrm{IL}$, as in our case, in $52.3 \%$ (14) $-76.6 \%$ (12) of the studied cases and lay in a mean distance of $1.52( \pm 0.84)(14)-1.89( \pm 0.48)(12) \mathrm{cm}$ from the anterior superior iliac spine, while the LFCN crossed the

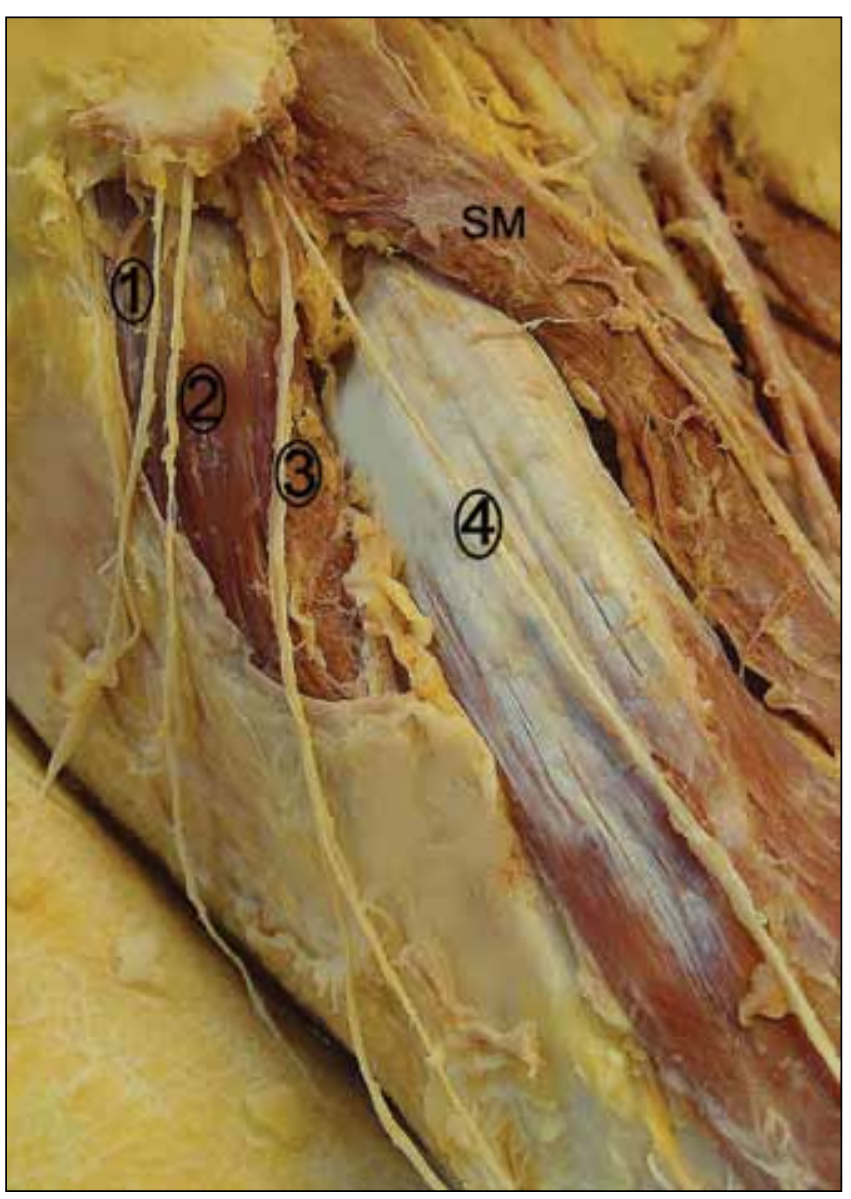

Figure 2: After passing underneath the inguinal ligament, the lateral and medial nerves took the place of the posterior and anterior LFCN branches, respectively. The posterior LFCN branch was found divided into a posterior (1) and an anterior (2) branch, while the anterior branch was bifurcated into a lateral (3) and a medial (4) branch, supplying the anterolateral aspect of the thigh. At the level of the inguinal ligament, four nerve branches are present (1-4). (SM: Sartorius Muscle). 


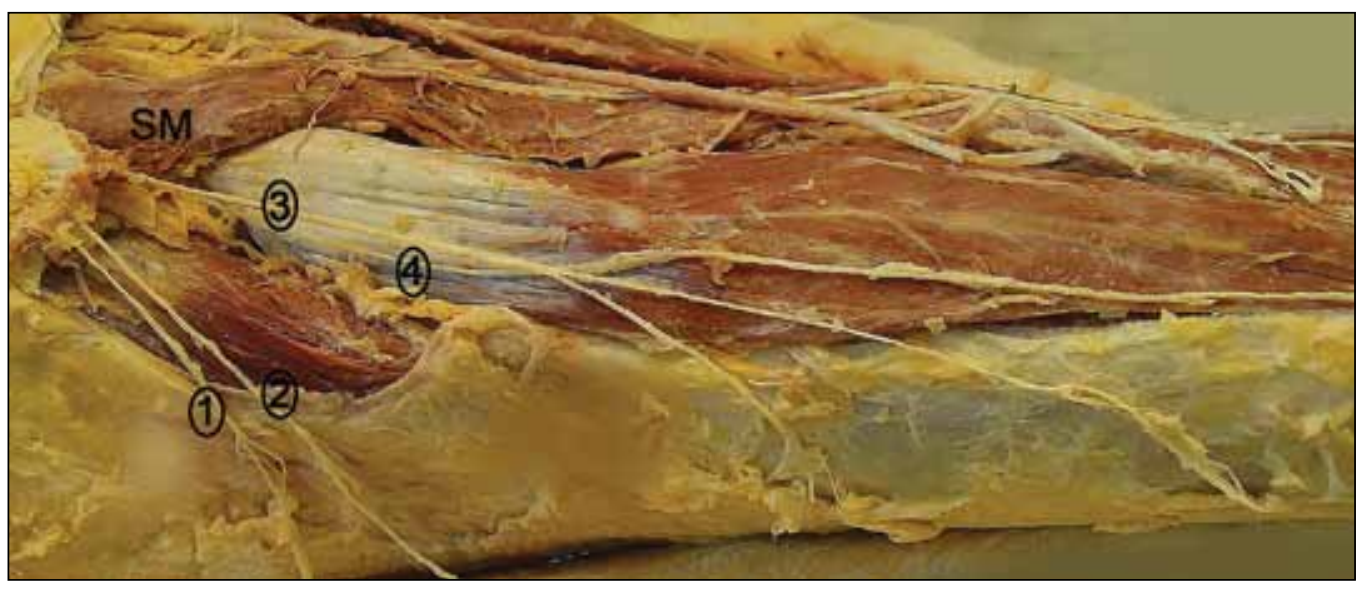

Figure 3: Distribution of the four nerve branches. The posterior ( 1 ) and anterior (2) branches of the posterior LFCN branch was distributed to the supero-lateral aspect of the thigh, while the lateral (3) and medial (4) branches of the anterior LFCN branch supplied the extended anterolateral aspect. (SM: Sartorius Muscle). sartorius muscle laterally in $64.5 \%$ (12). Origin of the LFCN from the femoral nerve has been noticed in $6 \%$ (1) to $10 \%$ (13) of the studied cases, whereas there is a documented case in which the LFCN was found arising from the femoral nerve, although the origin occurred below the level of the IL (3). In all these cases, the LFCNs were exclusively provided by the femoral nerve, while in our case, two LFCN branches were present. To our best knowledge, we were able to detect one similar case in the literature, in which an accessory LFCN branch was found arising from the femoral nerve in the pelvis (15). We should mention however that in the aforementioned case the supernumerary nerve had a subservient role, as it terminated early, after supplying the supero-anterior aspect of the thigh (15), whereas in our case the LFCN branch originating from the femoral nerve was not characterized as an accessory nerve branch due to its extended length and distribution.

LFCN is vulnerable to injury during multiple surgical procedures, as for example during extraperitoneal approach to the anterior lumbar spine (12), autogenous iliac bone grafting (9) and abdominal laparoscopic technique $(4,11)$. The surgeon of the area should be aware of the variability of the nerve anatomy and the possible existence of more than one nerve branches. If the surgeon is not familiar to the LFCN anatomic and topographic variability, after the initial surgical identification of the "main" nerve branch, iatrogenic injury of the supernumerary LFCN branches may occur. The lesion or entrapment of the LFCN results in sensory deficits and alterations over the distribution area of the nerve, thus the anterolateral aspect of the thigh. The diagnosis of meralgia paresthetica is based on clinical findings, electrophysiological studies, while local anesthetic and steroid injection at the nerve region has also been used as a diagnostic tool. In diagnosed cases of meralgia paresthetica, the existence of multiple LFCN branches could cause difficulties establishing a correct diagnosis, as in our case, the anesthetic injection test may be false negative due to the fact that the branch originating from the femoral nerve would preserve sensory supply over the area after the anesthetic block. In the presented case, the nerves pass underneath the IL, which consists a potential entrapment site (5). Therefore, the presence of four branches increases the chances of neuropathy appearance, whereas if symptomatology is present, the surgeon may not identify and decompress the responsible nerve branch during surgery, leading to symptoms persistence and necessity of re-operation.

The LFCN has also been utilized in plastic surgery, as appropriate graft for nerve reconstruction $(6,7)$. Therefore, in cases similar to ours, the supernumerary LFCN branches could be used as optimum vascularized grafts for sensory nerve repair. The technique includes harvesting of the nerve branch and its accompanying vessels, while the existent nerve overlapping is expected to compensate any sensory deficits over the LFCN supplied area. The LFCN branches can be visualized by ultrasound imaging, as sonographic identification of the LFCN is suggested to consist a feasible and accurate method that can be used in order to reveal nerve variations $(2,10)$. Consequently, it is obvious that knowledge of the anatomy and topography of the LFCN is significant for the physician and radiologist, in order to confirm a diagnosis, as well as for the surgeon in order to avoid postsurgical complications while intervening in the area or select an appropriate nerve graft in plastic and reconstructive surgery.

\section{REFERENCES}

1. Astik RB, Dave UH: Anatomical variations in formation and branching pattern of the femoral nerve in iliac fossa: A study in 64 human lumbar plexuses. PJSR 4(2):14-19, 2011

2. Damarey B, Demondion X, Boutry N, Kim HJ, Wavreille G, Cotten A: Sonographic assessment of the lateral femoral cutaneous nerve. J Clin Ultrasound 37(2):89-95, 2009

3. Dias Filho LC, Valença MM, Guimarães Filho FA, Medeiros RC, Silva RA, Morais MG, Valente FP, França SM: Lateral femoral cutaneous neuralgia: An anatomical insight. Clin Anat 16(4):309-316, 2003

4. Eubanks S, Newman L 3rd, Goehring L, Lucas GW, Adams CP, Mason E, Duncan T: Meralgia paresthetica: A complication of laparoscopic herniorrhaphy. Surg Laparosc Endosc 3(5): 381-385, 1993 
5. Ghent WR: Further studies on meralgia paresthetica. Can Med Assoc J 85:871-875, 1961

6. lida T, Nakagawa M, Asano T, Fukushima C, Tachi K: Free vascularized lateral femoral cutaneous nerve graft with anterolateral thigh flap for reconstruction of facial nerve defects. J Reconstr Microsurg 22(5):343-348, 2006

7. Kashiwa K, Kobayashi S, Nasu W, Kuroda T, Higuchi H: Facial nerve reconstruction using a vascularized lateral femoral cutaneous nerve graft based on the superficial circumflex iliac artery system: An application of the inferolateral extension of the groin flap. J Reconstr Microsurg 26(9):577-582, 2010

8. McMinn RMH: Last's Anatomy. Regional and applied. $8^{\text {th }}$ ed, Edinburgh: Churchill Livingstone, 1990:147

9. Murata $Y$, Takahashi $K$, Yamagata $M$, Sameda $H$, Moriya $H$ : Injury to the lateral femoral cutaneous nerve during harvest of iliac bone graft, with reference to the size of the graft. J Bone Joint Surg Br 84(6):798-801, 2002

10. Ng I, Vaghadia H, Choi PT, Helmy N: Ultrasound imaging accurately identifies the lateral femoral cutaneous nerve. Anesth Analg 107(3):1070-1074, 2008
11. Polidori L, Magarelli M, Tramutoli R: Meralgia paresthetica as a complication of laparoscopic appendectomy. Surg Endosc 17(5):832, 2003

12. Ray B, D'Souza AS, Kumar B, Marx C, Ghosh B, Gupta NK, Marx $A$ : Variations in the course and microanatomical study of the lateral femoral cutaneous nerve and its clinical importance. Clin Anat 23(8):978-984, 2010

13. Sim IW, Webb T: Anatomy and anaesthesia of the lumbar somatic plexus. Anaesth Intensive Care 32(2):178-187, 2004

14. Sürücü HS, Tanyeli E, Sargon MF, Karahan ST: An anatomic study of the lateral femoral cutaneous nerve. Surg Radiol Anat 19(5):307-310, 1997

15. Uzmansel D, Aktekin M, Kara A: Multiple variations of the nerves arising from the lumbar plexus. Neuroanatomy 5:3739, 2006

16. van Slobbe AM, Bohnen AM, Bernsen RM, Koes BW, BiermaZeinstra SM: Incidence rates and determinants in meralgia paresthetica in general practice. J Neurol 251(3):294-297, 2004

17. Williams P (ed): Gray's Anatomy. 38th ed, Edinburg: Churchill Livingstone, 1995: 1534-1535 